This is an Accepted Manuscript of an article published by Taylor\&Francis in Oxford Review of Education on 10/01/2014, available online:

http://www.tandfonline.com/doi/abs/10.1080/03054985.2013.875261\#.U6wrdPldVHU

Published details:

Rolleston, Caine and Sofya Krutikova (2014) "Equalising opportunity? School quality and home disadvantage in Vietnam", Oxford Review of Education 40 (1): 112-131. DOI:

$10.1080 / 03054985.2013 .875261$

This article is reproduced in accordance with the self-archiving policies of Taylor\&Francis. 


\title{
Equalising Opportunity? School Quality and Home Disadvantage in Vietnam
}

\author{
Caine Rolleston $^{1}$ and Sofya Krutikova ${ }^{2}$
}

\section{Notes on Contributors}

Dr. Caine Rolleston is a Lecturer in Education and International Development at the Institute of Education, University of London, UK and a Research Associate at Young Lives, University of Oxford, UK.

Dr. Sofya Krutikova is currently a Research Officer at Young Lives, University of Oxford, UK.

\section{Acknowledgements}

The authors would like to thank Angela W. Little and Zoe James for comments on earlier drafts of the paper and the Young Lives teams in Vietnam and Oxford.

\footnotetext{
${ }^{1}$ Institute of Education, University of London, 20 Bedford Way, London WC1H0AL Email: C.Rolleston@ioe.ac.uk

${ }^{2}$ Department of International Development, University of Oxford, Mansfield Road, Oxford OX1 3TB

Email: sofya.krutikova@qeh.ox.ac.uk
} 


\begin{abstract}
Levels of basic literacy and numeracy skills among Vietnamese primary school children are high by comparison with other countries of a similar income level and the country has made impressive gains in primary enrolment in recent years as well as improving the quality of schooling. Nonetheless, there remain substantial gaps in school performance between children from more and less advantaged backgrounds. Part of the justification of free public schooling consists in the equalisation of 'opportunities to learn' and the mitigation of learning inequalities which result from differences in home-background advantage. In this paper we examine the learning achievement of pupils in primary grade 5 and explore the relationships between home-background, teacher, peer and school factors and learning progress in grade 5, using data from Young Lives. We find that disadvantaged pupils receive relatively equitable access in relation to indicators of 'fundamental' school quality, a considerable policy success regarding the provision of 'minimum standards'. However, differences by home advantage are relatively large where more sophisticated 'opportunities to learn' are considered, such as the number of hours of instruction received, including through 'extra classes', as well as access to learning resources such as computers, internet and non-text books. Analysis of the predictors of attainment suggests that some of these are likely to constitute an important part of the explanation for the persistence of learning inequalities by home background in Vietnam, suggesting that following success in equalising basic inputs, policy attention should turn more directly to boosting wider 'opportunities to learn' among disadvantaged pupils.
\end{abstract}

\title{
Introduction
}

The challenge of raising learning levels among pupils in developing countries is an urgent one when examined using international test data, which suggest that the median child in poor countries has learning outcomes comparable to that of the child in the fifth percentile of the learning distribution in OECD countries (Filmer, Hassan and Pritchett, 2006). Policies to improve school quality are an important response, and Vietnam, where learning levels are comparatively high, has pursued a number of such policies, especially since the achievement of universal primary education. Several major initiatives have targeted disadvantaged pupils specifically, including the Primary Education for Disadvantaged Children (PEDC) project, which included the development of 'fundamental school quality levels' (FSQL), which serve as a national minimum benchmark ${ }^{1}$. Disadvantage linked to home backgrounds may be expected to impact negatively on pupils' learning in almost any context, while a link between disadvantage at home and access to lower quality schooling potentially compounds this relationship, leading to widening inequalities in learning between more and less advantaged pupils; and to wider social and economic inequalities. Policies intended explicitly to address inequalities in schooling by improving school quality in disadvantaged areas might be expected at least to mitigate these effects, through the equalisation of 'opportunities to learn' at the school level. However, there is considerable controversy in the literature concerning the detail of which school 'inputs' matter most for improving learning progress (see Glewwe et al, 2011), so that specific targeting of investments is not always straightforward.

Young Lives (YL) conducted a school survey in Vietnam during 2011-12, following a longitudinal design to measure learning in both mathematics and Vietnamese reading comprehension at entry to

\footnotetext{
${ }^{1}$ FSQL defines the minimum package of school inputs necessary for providing a 'quality education' and the basic outcomes expected of schools. Initially they comprised 17 indicators, rising to 35 in 2003. Standards include indicators of physical inputs and 'foundational opportunities to learn', many of which are among those found to have consistent positive effects on learning in the literature. They include blackboards, furniture, textbooks for every child, five days per year of in-service training for every teacher, minimum teacher qualifications, regular teacher evaluation and assessments of pupils, adequate hours of instruction and a parents' committee, but do not extend to resources such as libraries or computers (see Carr-Hill, 2011).
} 
and at the end of Grade 5. The survey included the 'younger cohort' sample of children (a birth cohort of pupils born in 1994/5) and their class peers, teachers and principals. In this paper we employ this data to examine the relationships between pupils' home advantage and their achievement in mathematics and Vietnamese and the relationships between pupils' backgrounds and measures of the quality of their schools, classes and teachers. These measures focus on indicators included in the FSQL standards as well as broader process indicators of 'opportunities to learn'. An innovative feature of the analysis is the inclusion of data on the characteristics of class peers, which, while recognised as important for individuals' learning, are often omitted from analysis of school quality and achievement. Our analysis focuses on gaps in school achievement between pupils from more and less advantaged backgrounds, documenting key differences in home and school characteristics, including in relation to class peers, which are expected to influence school achievement. We examine the associations between these characteristics and school attainment in a multiple regression framework, and draw together the evidence to highlight factors that are important for attainment and which differ by home advantage in ways which contribute to our understanding of key drivers of gaps in attainment among Vietnamese primary school pupils.

\section{Context and Literature}

Primary schooling in Vietnam is compulsory, and basic 'half-day' provision is free of charge, while fees are often levied for 'full-day' schooling and many families also pay for other forms of supplementary education. Children normally start school in the calendar year in which they become 6 and progress through five primary grades, studying six subjects in addition to maths and Vietnamese. Overall, Vietnamese children receive a relatively low number of hours of instruction by international standards, with around 59 per cent of pupils attending 'full-day' schooling in 2008-09, while the extension of 'full-day' schooling to the remainder is set to be achieved by 2020 (World Bank, 2011). The vast majority of primary school pupils attend a local public school and government policy requires that a public primary school be located in every commune. While there are a small number of semi-public, 'people-founded' and fully-private schools, only half of one per cent of primary pupils attended fully-private schools in 2011 (World Bank, 2013). De facto privatisation of the form seen elsewhere has been very limited, but the government's 'socialisation' policies (see London, 2011), which require greater 'cost-sharing'; in combination with rising incomes, have led to increases in household spending on education, especially by more advantaged households and in the form of extra (private) tuition (Carr-Hill, 2011).

Vietnam has experienced robust economic growth and poverty reduction since economic liberalisation (đổi mới ) in 1986 and spends a relatively high proportion of public expenditure on education at around 20 per cent (World Bank 2011:6). Legislation to universalise primary education was implemented in 1991 and by the turn of the twenty-first century this had practically been achieved, with an attendance rate of $94 \%$ by 2004 (World Bank 2011). Since 2000, basic education policies have focused squarely on qualitative improvements, while a falling birth rate and school-age population have reduced pressure on the primary school system. The shift in policy focus from 'quantity to quality' was set out explicitly as the first strategic goal in the national Education for All Plan for 2003-13 (Attfield and Vu, 2012) and has been pursued through a number of important reforms, including extensive renovation of curricula, text-books and teacher training (see Griffin and Mai Thanh, 2006; World Bank 2004a). Nationally representative assessments among Grade 5 children were conducted by the Vietnamese Ministry of Education and Training (MoET) in 2001, 2007 and 2011 (see World Bank 2004a, 2004b) and found (for 2001) that learning levels were particularly low in 'isolated areas' (Griffin and Mai Thanh, 2006; Griffin, 2007). These areas also showed the least 
improvement by 2007 (World Bank 2011:52). Over this period, however, learning levels in maths and reading improved substantially overall, as did attendance (World Bank, 2011). FSQL data showed notable improvements between 2003 and 2008/9, especially on teacher training, teaching materials and the quality of school infrastructure, with a rise in the overall FSQL index from 62 to $71 \%$ (World Bank, 2011).

Although no internationally comparable test data are yet available for Vietnam, indicative comparisons suggest that learning levels in mathematics and reading at primary level are high, comparing in some cases to much more economically developed countries (World Bank 2011). Despite this, gaps in learning achievement between the most and least advantaged groups, the latter including ethnic minorities, remain relatively wide, with potentially important consequences for social mobility. More than $70 \%$ of ethnic minorities are in the bottom three consumption deciles and the gap between Kinh and ethnic minorities with the same years of schooling is reported to be up to half of a standard deviation in test scores, linked to differences in school quality and parental education, among other factors (Dang, 2012).

The literature on the impacts of school and teacher quality on pupil achievement in the 'education production function' (EPF) framework is extensive, but differences in methodology and results, as well as between contexts, produce a somewhat inconclusive picture with regard to the importance of individual indicators; and there is very little evidence on the relative cost-effectiveness of improving particular inputs. Nonetheless, Fuller and Clarke's (1994) review of the literature finds a high degree of consistency with regard to the positive effects of textbooks and learning materials, teacher characteristics (especially subject knowledge) instructional time and work demands. Glewwe et al's (2011) more recent review supports this in general terms, while raising methodological concerns. They find reasonably consistent effects, across 43 'high quality' studies, of infrastructure, furniture, blackboards, libraries, instructional time, additional tutoring and the assignment of homework; and of teacher subject knowledge, in-service training and absenteeism. In a wider sample of 79 studies, effects of textbooks, electricity, teacher and principal experience, pupil attendance and pedagogic style are also found. Somewhat consistent with the evidence from EPF studies, McKinsey's study of improving school systems finds that in less developed systems, the transition 'from poor to fair' performance is characterised by quantitative expansion - 'getting students in seats'; by 'getting all schools to a minimum quality level' and by 'providing motivation and scaffolding for low skill teachers' (McKinsey, 2010:28). More specifically, instructional time, school visits by the centre, basic infrastructure, outcome targets, textbooks and additional support for low performing schools are included among the intervention areas identified (McKinsey, 2010).

Basic physical inputs may be a necessary condition for pupil learning, but they are not sufficient in the absence of adequate 'opportunities to learn' (OtL). OtL approaches emphasise 'time and effort' indicators specifically. A USAID review of the literature identifies six 'foundational opportunities to learn' in the domain of 'inputs and managements' - instructional time, school availability and opening, teacher and pupil attendance, pupil-teacher ratio (PTR) and the availability of instructional materials; alongside two in the domain of 'pedagogy' - effective use of time and the development of core reading skills by the third grade (USAID 2012:11). More sophisticated dimensions of OtL beyond the foundational include those concerned with 'proportionate curricula' and 'high expectations' (USAID 2012), also considered in Cueto et al. (2013) (in this volume). The evidence from Vietnam's national assessments of Grade 5 is broadly congruent with that from the international literature overall, with effects including those of instructional time, textbooks, homework, libraries, 
teacher experience, knowledge (assessed only in 2001; see Griffin (2008)), 'excellence' and evaluation being identified (World Bank, 2011).

A related, though usually separate, strand of literature on the determinants of pupil attainment addresses the effects of school peers (see Sacerdote (2011) for an overview). Much of the evidence suggests that both the background characteristics of class peers and their attainment matter for individual attainment. Characteristics emphasised in the literature include gender, ethnicity and socioeconomic status (Lavy \& Schlosser, 2011). While existing evidence on peer effects is based primarily on data from the United States and Europe, a growing literature presents broadly consistent evidence for developing country contexts, including for the Philippines, Chile, South Korea and China (Glewwe, 1997; McEwan, 2003; Kang, 2007; Ding and Lehrer, 2007).

\section{Data}

The Young Lives school survey was conducted in 20 sites in five provinces in Vietnam - Ben Tre, Da Nang, Hung Yen, Lao Cai and Phu Yen ${ }^{2}$. All schools within the sites which were attended by one or more of the younger cohort of children in primary grade 5 were included. To achieve a balanced sample at class-level, the sample of index children was augmented by adding their class peers to a total of 20 pupils per class, following a randomisation procedure. The final sample comprises 3,284 Grade 5 pupils (of whom 1,138 are Young Lives index children) in 176 classes in 56 schools or 91 school sites (where 'satellite schools' are considered separately). The survey included questions which cover a range of school and teacher quality indicators, including several which appear in the FSQL, plus wider indicators of foundational and more sophisticated OtL.

Pupils completed a background questionnaire focusing on their homes, families and education-related resources and on their time-use, including homework and attendance at 'extra classes'. Around 12 per cent of pupils came from ethnic minority backgrounds and, while the sample is not representative of ethnic minority groups, this is similar to the national figure of 14 per cent (Dang, 2012). Pupil tests in mathematics and Vietnamese employed a 30-item multiple-choice format developed by Young Lives in line with those employed in the MOET Grade 5 Study, to measure learning levels in relation to curricular expectations. Tests were administered at the beginning and at the end of the school year. The first and second tests contained a set of common 'anchor' items which permit the equating of the two tests on a common interval scale using analysis based on item-response theory (IRT). The mean test score in the initial tests was fixed at 500 and the standard deviation at 100 for ease of interpretation and in common with the MOET Grade 5 study and with international comparative assessments. The initial tests were designed to measure learning levels at entry to Grade 5 (on prior curricula), while the end-of-year tests also included items from the Grade 5 curriculum. Table 1 shows examples of 'anchor' items used in maths. Absenteeism in the sample was low and a comparable score on both tests is available for more than 97 per cent of the sample in both subjects.

[Table 1]

\section{Analysis: Descriptive Statistics}

We measure pupils' 'home background advantage' using an index computed using principal components analysis (PCA) of data on home backgrounds, including household-level portable asset

\footnotetext{
${ }^{2}$ Full details of the Young lives sampling strategy and survey design are available in Boyden and James (2014) in this volume.
} 
ownership and indicators of the home environment in terms of Vietnamese language and literacy ${ }^{3}$. Table 2 shows that disadvantaged pupils' test scores are markedly lower than those of their more advantaged peers, with a difference of around one standard deviation in both subjects between the top and bottom quintile at the first test. This equates to approximately two years' average learning among the most disadvantaged pupils in maths and two and a half years in Vietnamese. By the time of the second test, the gap between the scores of the most and least disadvantaged pupils in relation to mastery of intended curricula is found to have narrowed somewhat. The raw correlation between the first and second test-scores is 0.54 in maths and 0.46 in Vietnamese.

[Table 2]

Table 3 reports the mean values of the variables used in constructing the 'home background index' by quintile of the index plus the PCA loading for each. The PCA loadings indicate that the variables weighted most heavily in the construction of the index are those associated with Vietnamese literacy and home learning resources, including study chair, desk, computer, lamp and a pupil's 'own place to study'. Based on this analysis, very large differences are observed between the most and least advantaged pupils in terms of access to computers, calculators and the internet, ownership of a study desk/chair/lamp and on whether pupils have their own place to study or have more than ten books (other than school books) at home.

\section{[Table 3]}

In order to examine the relationship between learning progress and home backgrounds, a regression model was employed to predict each pupil's end of Grade 5 attainment in each subject (their 'expected score'), using their initial scores in both subjects only as predictors ${ }^{4}$. The 'expected score' is therefore based on the average relationship between first and second test scores with no adjustments for home backgrounds. Table 4 reports the results. On average, the most advantaged pupils 'overperformed' at the second test in both subjects in relation to their 'expected scores', while the most disadvantaged pupils' scores were not significantly different from expected i.e. from the scores of pupils with the same initial scores regardless of background. Pupils in the second most disadvantaged quintile, however, did show 'under-performance' in relation to 'expected scores' based on their prior scores. These differences are expected to reflect both the influence of home background effects within the school year and the influence of differences in school quality accessed by pupils at different levels of home background advantage. Overall, differences are relatively small.

\section{[Table 4]}

Our analysis finds relatively large gaps in attainment by home advantage at entry to grade 5 which have narrowed somewhat by the end of the year. However, when comparing pupils with similar test scores at the beginning of the year, we find that the most advantaged pupils do make greater learning gains. We proceed to examine differences in pupil, school, class, teacher and class peer indicators of quality and opportunities to learn. Table 5 reports the mean values of key school-level quality indicators by quintile of pupil home advantage and the differences between the highest and lowest quintiles. These differences are significant at the $1 \%$ level for all variables. Very small differences

\footnotetext{
${ }^{3}$ This is in-line with the approach used in World Bank's Grade 5 study (World Bank 2004b) and in Hungi (2008). The first principal component accounts for $24.0 \%$ of the variance among the indicators included.

${ }^{4}$ The regression model includes linear, quadratic and cubic terms for scores at the first test in both subjects (to reflect non-linearity), used to estimate a predicted value for the second test score in each subject for each pupil based on the fitted relationship.
} 
are observed in relation to basic facilities (including FSQL standards) such as the availability of electricity, the provision of a separate room for each grade 5 class and whether principals had received the required three years' pre-service training or more. Disadvantaged pupils are not found to be in schools with less experienced principals, principals who had received less in-service training or schools which were closed for more days as a result of unforeseen circumstances. They are, however, found to be in schools which receive fewer inspection visits, have lower assets overall and which are more likely to have 'failing infrastructure'. Differences by home advantage emerge more strongly when going beyond 'minimum standards' to more nuanced measures of OtL. Most notably, disadvantaged pupils are considerably less likely to be in schools with libraries, computer facilities, internet accessible to pupils and principals educated to university degree level or who had been awarded the status of 'excellent teacher'.

\section{[Table 5]}

Table 6 reports mean class and teacher-level quality indicators, by quintile of pupil home advantage. Again, differences on basic resources such as the availability of a teacher's desk, blackboard, electric lighting, furniture and core textbooks are small, while statistically significant except in the case of blackboards. On the other hand, disadvantaged pupils potentially benefit from smaller class sizes, teachers with slightly lower absence, who were evaluated more often, taught fewer teaching periods per week, checked homework more frequently and who were slightly more likely to have been awarded 'excellent teacher' status. Further, teachers of disadvantaged pupils reported setting more homework tasks in maths and Vietnamese and less often reported that schooling was affected by 'interruptions to teaching'. Differences in terms of teachers', experience, pre-service training are found to be relatively small, although these indicators are lower for the most disadvantaged pupils. These results suggest small differences on FSQL standards. However, in terms of a number of indicators of OtL, including the number of hours of instruction received in maths, Vietnamese and in total, differences favour the most advantaged pupils, who on average received an additional three periods (of 45 minutes) of teaching per week when compared to the least advantaged. Their classrooms were less likely to need major repairs, had more assets overall, were more likely to have a computer and books other than textbooks and their teachers less often reported a problem of a 'lack of materials among pupils'. Teachers of more advantaged pupils were slightly more likely to have a university degree and achieved slightly higher scores in assessments of their 'pedagogical content knowledge ${ }^{5}$ ' in maths and in Vietnamese. All of the differences reported are statistically significant.

The characteristics of pupils used to construct the advantage index are primarily household characteristics, but a range of other pupil-level indicators reflect both home and school influences. For example, the time pupils spend on homework may be linked to their teacher's setting of homework tasks and the level of support at home. Table 7 reports a set of indicators of this type, by pupil advantage quintile, including the differences between the highest and lowest quintiles, all of which are significant at the $1 \%$ level. Disadvantaged pupils are found to spend longer travelling to $\mathrm{school}^{6}$, are less likely to report reading books outside school, spent an average of around twenty minutes less on homework per day, were absent from school for slightly more days and were more likely to have repeated a grade. However, absence was very low for pupils of all levels of home advantage and grade repetition is also generally low. The most notable differences relate to learning opportunities outside of school or beyond minimum standards of provision, such as using a computer and attendance at

\footnotetext{
${ }^{5}$ Teachers completed a 25 item multiple choice test of 'pedagogical content knowledge' (PCK) which employed examples of pupil's mistakes and assessed teachers' understanding of how such mistakes might arise

${ }^{6}$ Although for pupils of all backgrounds, distances to school are typically short.
} 
'extra classes'. Only a fifth of the most disadvantaged pupils attended such classes, compared to almost three fifths of the most advantaged pupils, with the most advantaged attending around one hour more of extra tuition per week in each of maths, Vietnamese and other subjects on average. Also, the possession of learning materials for maths and Vietnamese by pupils 'for their own use' varied notably by home advantage.

\section{[Table 6]}

\section{[Table 7]}

Finally, Table 8 presents a selection of notable average characteristics of a pupil's class peers, by individual pupil home advantage quintile. Fairly large differences are found on attainment and home advantage, indicating that disadvantaged pupils tended to have lower achieving and more disadvantaged class-peers. In line with this trend, large differences in favour of more advantaged pupils were also found in peers' opportunities to learn outside school, including use of computers outside school, hours of extra classes attended and ownership of learning materials. As indicated in Table 8, comparison of the peers of children in the highest and lowest home advantage quintiles show that all of the differences are statistically significant. To the extent that peer characteristics and attainment affect pupil attainment (as has been found in the literature), these differences in peer groups by home advantage may constitute an important mechanism for the persistence of attainment gaps between pupils from more and less advantaged backgrounds.

[Table 8]

\section{Regression Analysis}

Having established some of the key differences in school inputs and opportunities to learn between Grade 5 pupils from different socio-economic groups in our sample, we proceed to investigate the relationship between these factors and school achievement. We employ regression analysis in a 'value-added' framework, using test scores at the end of the year as the outcome with prior scores included as explanatory variables ${ }^{7}$. We include the child, class, peer and teacher-level variables presented in Tables 4 to $7^{8}$. Table 9 presents the results of 'ordinary least squares' (OLS) and 'school fixed effects' (SFE) models for maths and Vietnamese. The SFE models provide a more robust estimate of 'within school' relationships by taking account of unobserved omitted school-level influences and non-random 'selection into schools'. An additional concern might be non-random selection into classes even within schools. In the Vietnamese context, most often, pupils are not selected into classes by ability however and moreover, the models include a rich set of controls for individual characteristics including prior test scores, which are likely to capture important unobserved individual level heterogeneity, substantially alleviating concerns about omitted variable bias ${ }^{9}$. We are only able to report significant findings due to the large number of variables included in the models. Owing to the relatively small number of schools we do not focus on school-level variables, although we include these as controls in the OLS models (not reported).

\footnotetext{
7 Prior scores in both subjects include quadratic and cubic terms to reflect non-linearity. These are not interpreted and are omitted from Table 9 owing to the large number of variables of interest.

${ }^{8}$ In addition we add controls for home advantage, age and sex (in all models) and for school-size, satellite school and multi-grade teaching (in OLS). We do not include variables with almost no variation - teacher's desk, blackboard, lighting, furniture, core textbooks and remove a number variables to avoid collinearity attends extra classes in any subject, teacher workload (periods per week), class assets index, pupil learning materials, school assets index, 'problem of lack of resources among pupils' and peer learning materials.

${ }^{9}$ Only 8 out of 91 school sites reported that ability selection was used for allocation of pupils into classes.
} 
Results show some indication that class resources matter for individual attainment. There is a negative association between the need for repairs to the classroom and attainment, especially in Vietnamese, while the evidence on availability of resources relevant for learning is more mixed, with typically positive associations between learning and the availability of computers, but a surprising negative association with the availability of books other than text books (in the SFE models). Variation in teacher qualities along a number of dimensions is significantly associated with attainment. While no clear picture emerges on teacher training or in-service training, specialisation in maths is found to be positively associated with attainment. Teacher experience is also positively associated with pupil attainment, as are more frequent teacher evaluation and higher performance on teacher tests (for pupils' maths learning). Although absenteeism is much lower than in other developing country contexts, the number of days teacher was absent in the previous year is negatively associated with performance, especially for Vietnamese learning. Finally, the data capture some relevant aspects of classroom processes. Performance, especially in maths, is lower in classes that experience interruptions to teaching and higher for classes with teachers who always check maths homework. There is some evidence of competition for limited homework time, with the number of homework tasks set in Vietnamese being negatively associated with attainment in maths, and a similar pattern for number of homework tasks set in maths and attainment in Vietnamese.

Our analysis includes prior attainment scores which are likely to absorb much of the effect of the individual characteristics on attainment except those which persist during Grade 5 specifically. Nonetheless, some patterns emerge. There are consistent positive associations between attainment in one or both subjects and time spent on homework, reading outside school, attending extra classes in 'other subjects' (especially on maths learning), and using computers outside school ${ }^{10}$. There is some indication of selection into extra classes in maths and Vietnamese by weaker students. Additional individual characteristics that are negatively associated with attainment include having repeated a grade in the past and living further away from the school.

Some of the associations between individual characteristics and attainment are also reflected in the results for the characteristics of class peers. All of the specifications include controls for both peer characteristics and performance. In order to reduce concerns about reverse causality between peer and child performance, we use lagged peer test scores (from tests at the beginning of the year) instead of contemporaneous scores. The scores can be viewed as a summary measure of peer "quality", also captured by the set of specific controls for peer characteristics. The specifications controlling for school fixed effects suggest that if anything peer performance is negatively associated with own performance, especially in Vietnamese. Further the estimates suggest that attainment is not the only channel through which peers affect child performance. For example, attendance at extra classes in Vietnamese and maths by class peers is negatively associated with pupil attainment, perhaps reflecting the negative effect of having higher achieving peers (as also indicated by the negative association between peer and own attainment). Further, there is some indication of a positive association between class peers reading books and using computers outside of school (especially for maths) and the individual pupil's attainment. Finally, individual attainment appears to be adversely affected by presence of grade repeaters in the class, an indicator of performance in previous years, as well as by a larger proportion of boys in the peer-group. The relationship between individual attainment and the home advantage of class peers is more sensitive to specification, while the more

\footnotetext{
${ }^{10}$ This association is positive though imprecisely estimated in most of the models
} 
robust SFE estimates suggest a strong positive association between mean peer home advantage index and attainment in Vietnamese.

[Table 9]

\section{Discussion and Conclusions}

At entry to Grade 5, pupils' attainment levels reflect the cumulative effects of background and school factors to date. The issues addressed in this paper relate more specifically to pupils' experience within Grade 5. In relation to curricular expectations in maths, the most disadvantaged quintile of pupils attained scores at the end of Grade 5 which were close to the mean for all pupils at the beginning of the year (see Table 2), while the gap was somewhat wider in Vietnamese, a subject in which home disadvantage of the individual pupil and his or her peers are found to affect learning levels negatively, linked to the importance of home language and the home literacy environment in the home advantage index. On basic physical inputs, there is considerable equity of access to school quality. The overwhelming majority of pupils at all levels of home advantage had access to standard text-books for their own use and their classrooms almost always had adequate furniture, a blackboard and electric lighting, each of which is shown to have a positive effect on learning in the literature.

Beyond physical inputs, there is notable equity in relation to a number of 'foundational OtL' which are expected to exert positive influences on learning. Absenteeism among pupils and their teachers is very low at all levels of advantage, schools are rarely closed for unforeseen reasons, including those attended by disadvantaged pupils; and the vast majority of pupils are in a class with an acceptable pupil-teacher ratio, being less than 1:23 for the most disadvantaged pupils. While higher levels of teacher absenteeism were found to impact negatively on test-scores in Vietnamese, and 'interruptions to teaching' in maths, disadvantaged pupils are not taught by teachers with higher levels of absence on average nor are they more affected by 'interruptions to teaching'. They are slightly more likely to be taught in a classroom in need of major repairs, however, a characteristic also found to exert a negative effect on learning in Vietnamese. The vast majority of pupils of all levels of advantage are taught by a teacher (and have a principal) who meets FSQL standards of pre-service training, and who is regularly evaluated, sets regular homework and receives in-service training in line with FSQL standards. Their schools also receive regular inspection visits. While there are likely to be further benefits of reaching the FSQL benchmarks in each and every primary school in Vietnam, results indicate considerable policy success to date in equalising access to 'minimum standards' of school resourcing across pupils of all levels of home advantage, potentially offering policy lessons for countries at earlier stages of educational development. Moreover, while the most disadvantaged pupils' learning during Grade 5 falls behind that of the most advantaged, taking account of prior attainment, the gap between the most disadvantaged and all other groups is relatively narrow, suggesting that a large fraction of the gap in overall learning levels originates in lower grades of schooling or earlier.

There is some evidence, however, that advantaged pupils are more likely to have teachers with key characteristics that are also positively associated with learning. Disadvantaged pupils are slightly less likely to be taught by teachers who had specialised in maths, for example. Moreover, they are taught by teachers with slightly lower levels of subject knowledge (PCK), found to be positively associated with learning in maths, and of pre-service training and experience, the second of which is also positively correlated with attainment in both subjects. While teachers of disadvantaged pupils attended more days of in-service training on average, this was found more often to be negatively associated with learning, perhaps because less effective teachers received more of this training or 
because of the consequent reduction in teaching time. Differences are larger in relation to two other 'foundational OtL' - instructional time and learning materials other than core textbooks, partly because these are linked to family resources, since parents bear a share of the responsibility for the costs. These findings suggest that future policies to equalise OtL may need to focus on quality standards above the established 'fundamental' levels, for example through efforts to improve teacher subject knowledge in disadvantaged areas.

With regard to the composition of peer groups, results suggest both that there are significant differences between the peer-groups of more and less advantaged pupils and that peer-group composition across certain dimensions is strongly associated with attainment. Clearly the relationship with attainment is not straight-forward as is shown in the literature and evidenced by for instance the mixed associations between peer home advantage and pupils' attainment. However, the results presented suggest that class peers are likely to constitute a highly relevant factor in explaining gaps in attainment which to be given more attention outside the sphere of specialised 'peer effects' studies.

While we have focused on the role of school characteristics in explaining gaps in learning among children from more and less advantaged households, we have also highlighted some key differences in opportunities to learn available to children from more and less advantaged backgrounds outside of school, including of extra tuition in 'other subjects'. In an analysis of the Vietnamese Household and Living Standards Survey (VHLSS) data from 2006, Carr-Hill (2011) finds the richest quintile of households spent twenty times more than the poorest on tuition, compared to seven times more on education as a whole and he argues that "increased expenditures will bring more benefit to the children in the richer households than to the children in the poorer households, especially when they were targeted, as in this case, on tuition". Disadvantaged pupils are found to receive fewer hours of instruction and of extra tuition, but the effects of these are consistently positive only where they are in subjects other than maths and Vietnamese. There is debate in Vietnam concerning how to allocate additional teaching hours when schools make the transition to 'full-day' schooling, concerning the extent to which focus should be on strengthening the delivery of core subjects versus widening the curriculum. The results presented here may be taken as suggestive that instructional time is generally adequate in maths and Vietnamese, while further research of the impacts of instructional time is required, taking into account the 'trade-offs' which exist within a finite total number of learning hours overall, as illustrated in the apparent cross-subject effects of homework time. Finally, future policies might consider the potential impacts of efforts to minimise the negative effects of disadvantaged pupils having weaker access to learning opportunities such as computers and books at home (and of their spending less time on homework) by strengthening these opportunities at school, through attention to the provision of computers, libraries and homework-support at schools in disadvantaged areas.

\section{References}

Attfield, I and B. T. Vu (2012) A Rising Tide of School Standards - The Role of Data Systems in Improving Equitable Access for All to Quality Education in Viet Nam. International Journal of Educational Development 33(1), 74-87

Boyden, J. and Z. James (2014) Schooling, Childhood Poverty and International Development: Choices and challenges in a longitudinal study Oxford Review of Education (forthcoming) 
Carr-Hill, R. (2011) A Large Scale Donor Attempt to Improve Educational Status of the Poor and Household Income Distribution: The Experience of PEDC in Vietnam. International Journal of Educational Development 31(3), 251-261

Cueto, S., G. Guerrero, J. Leon, M. Zapata and S. Freire (2014) Socioeconomic Status at age 1, Opportunities to Learn and Achievement in Mathematics Ten Years Later: A Study in Peru. Oxford Review of Education (forthcoming)

Dang, Hai-Anh (2012) 'A Widening Poverty Gap for Ethnic Minorities' in G. Hall and H. Patrinos (eds.) (2012) Indigenous Peoples, Poverty and Development. New York, Cambridge University Press.

Ding, W. and S.F. Lehrer (2007) Do Peers Affect Student Achievement in China's Secondary Schools? The Review of Economics and Statistics 89(2), 300-312.

Filmer, D., A. Hassan and L. Pritchett (2006) A Millennium Learning Goal: Measuring Real Progress in Education. Center for Global Development Working Paper 97

Fuller, B. and P. Clarke (1994) Raising School Effects While Ignoring Culture? Local Conditions and the Influence of Classroom Tools, Rule and Pedagogy. Review of Educational Research 64(1)

Glewwe, P. (1997) Estimating the impact of peer group effects on socioeconomic outcomes: Does the distribution of peer group characteristics matter? Economics of Education Review 16(1), 39-43

Glewwe, P., E. Hanushek, S. Humpage, R. Ravina (2011) School Resources and Educational Outcomes in Developing Countries: A Review of the Literature from 1990 to 2010. NBER Working Paper 17554 Cambridge, National Bureau of Economic Research

Griffin, P. (2007) Mathematics Achievement of Vietnamese Grade 5 Pupils. Asia Pacific Education Review 8(2), 233-249

Griffin, P (2008) Linking pupil and teacher competence in reading and mathematics in Vietnam Assessment in Education: Principles, Policy and Practice 7, 57-70

Griffin, P. and M. T. Thanh (2006) Reading Achievements of Vietnamese Grade 5 Pupils. Assessment in Education: Principles, Policy and Practice 13(2), 155-177

Hungi, N (2008) Examining differences in mathematics and reading achievement among Grade 5 pupils in Vietnam. Studies in Educational Evaluation 34, 155-164

Kang, C. (2007) Classroom peer effects and academic achievement: Quasi-randomization evidence from South Korea Journal of Urban Economics 61(1), 458-495

Lavy, V. and A. Schlosser (2011) Mechanisms and Impacts of Gender Peer Effects at School American Economic Journal: Applied Economics 3, 1-33

London, J (2011) 'Historical Welfare Regimes and Education in Vietnam' in London, J. (ed.) Education in Vietnam. Institute of Southeast Asian Studies, Singapore

McEwan, P.J. (2003) Peer effects in student achievement; Evidence from Chile" Economics of Education Review 22(1), 131-141 
McKinsey (2010) How the World's most improved school systems keep getting better. New York, McKinsey and Company

Sacerdote, B. (2011) Peer Effects in Education: How Might They Work, How Big Are They and How Much Do We Know Thus Far? In E. Hanushek, S. Machin and L. Woessmann (eds.) (2011). Handbook of the Economics of Education Volume 3, Elsevier

USAID (2012) Opportunity to Learn: A High Impact Strategy for Improving Educational Outcomes in Developing Countries. Washington D. C., USAID

World Bank (2004a) Vietnam Reading and Mathematics Assessment Study, Volume 1, Washington D.C., World Bank

World Bank (2004b) Vietnam Reading and Mathematics Assessment Study, Volume 2, Washington D.C., World Bank

World Bank (2011) Viet Nam High Quality Education for All by 2020, Washington D.C., World Bank

World Bank (2013) World Development Indicators, available at: http://data.worldbank.org/indicator (accessed $5^{\text {th }}$ October 2013) 
Table 1: Example questions from the maths test

\begin{tabular}{ll}
\hline Curriculum topic & \multicolumn{1}{c}{ Question } \\
\hline Number series & Fill-in the missing number: $1,3, \ldots, 27$ \\
Units of measurement & Fill-in the missing number: $9,000,000 \mathrm{~m}^{2}=\ldots \mathrm{km}^{2}$ \\
Mixed equations & Calculate: $(20+20) /(4 \times 5)$ \\
Arithmetic problems & Nhung sold 60 newspapers and Huong sold 80 newspapers, at the same price. The \\
& total amount of money they got from selling newspapers is 700,000 Dong. How \\
& much money did Huong get from selling the newspapers?
\end{tabular}

Table 2: Pupils' test scores

\begin{tabular}{lrrrrrr}
\hline Home advantage quintile & $\mathbf{1}$ & $\mathbf{2}$ & $\mathbf{3}$ & $\mathbf{4}$ & $\mathbf{5}$ & Total \\
\hline Maths Score (first test) & 447.1 & 483.9 & 499.5 & 519.0 & 543.0 & 500.0 \\
Maths Score (second test) & 501.1 & 521.8 & 535.6 & 554.6 & 579.8 & 540.1 \\
Vietnamese Score (first test) & 442.2 & 488.9 & 501.3 & 518.2 & 541.9 & 500.0 \\
Vietnamese Score (second test) & 479.7 & 498.7 & 514.0 & 522.6 & 548.3 & 513.9 \\
\hline
\end{tabular}

Table 3: Home background indicators used in the creation of a home advantage score

\begin{tabular}{lrrrrrrl}
\hline Quintile of home advantage & $\begin{array}{l}\text { Q1 } \\
\text { Mean }\end{array}$ & $\begin{array}{l}\text { Q2 } \\
\text { Mean }\end{array}$ & $\begin{array}{l}\text { Q3 } \\
\text { Mean }\end{array}$ & $\begin{array}{l}\text { Q4 } \\
\text { Mean }\end{array}$ & $\begin{array}{l}\text { Q5 } \\
\text { Mean }\end{array}$ & $\begin{array}{l}\text { Total } \\
\text { Mean }\end{array}$ & $\begin{array}{l}\text { PCA } \\
\text { Loading }\end{array}$ \\
\hline Landline telephone & 0.16 & 0.19 & 0.24 & 0.47 & 0.72 & 0.37 & 0.16 \\
Television & 0.79 & 0.95 & 1.00 & 1.00 & 0.99 & 0.95 & 0.21 \\
Study desk & 0.49 & 0.92 & 0.98 & 1.00 & 0.97 & 0.88 & 0.29 \\
Fan & 0.67 & 0.86 & 0.96 & 0.97 & 0.97 & 0.89 & 0.20 \\
Computer & 0.01 & 0.03 & 0.07 & 0.22 & 0.73 & 0.23 & 0.23 \\
Mobile phone & 0.77 & 0.88 & 0.95 & 0.98 & 0.97 & 0.91 & 0.14 \\
Bicycle & 0.57 & 0.85 & 0.94 & 0.95 & 0.96 & 0.86 & 0.18 \\
Study chair & 0.51 & 0.90 & 0.98 & 0.99 & 0.97 & 0.87 & 0.27 \\
Air conditioning & 0.00 & 0.02 & 0.03 & 0.06 & 0.40 & 0.11 & 0.17 \\
Internet & 0.01 & 0.02 & 0.04 & 0.12 & 0.64 & 0.18 & 0.21 \\
Radio & 0.09 & 0.17 & 0.22 & 0.27 & 0.54 & 0.27 & 0.14 \\
Motorcycle & 0.74 & 0.86 & 0.91 & 0.95 & 0.97 & 0.89 & 0.15 \\
Study lamp & 0.25 & 0.54 & 0.87 & 0.97 & 0.94 & 0.72 & 0.26 \\
Car & 0.03 & 0.03 & 0.04 & 0.06 & 0.23 & 0.08 & 0.10 \\
Calculator & 0.10 & 0.22 & 0.25 & 0.38 & 0.58 & 0.32 & 0.18 \\
Pupil has 'own place to study' & 0.40 & 0.75 & 0.88 & 0.96 & 0.97 & 0.80 & 0.25 \\
Number of meals eaten by pupil per day $\geq 3$ & 0.74 & 0.76 & 0.81 & 0.92 & 0.91 & 0.83 & 0.07 \\
Number of books in the home (>10) & 0.16 & 0.33 & 0.34 & 0.65 & 0.75 & 0.45 & 0.22 \\
Pupil speaks Vietnamese at home (always) & 0.62 & 0.97 & 0.99 & 1.00 & 0.98 & 0.91 & 0.30 \\
Pupil is from and ethnic minority group & 0.48 & 0.10 & 0.02 & 0.01 & 0.03 & 0.12 & -0.29 \\
Mother is literate in Vietnamese & 0.64 & 0.97 & 0.99 & 1.00 & 0.99 & 0.92 & 0.30 \\
Father is literate in Vietnamese & 0.80 & 0.94 & 0.99 & 1.00 & 1.00 & 0.95 & 0.20 \\
\hline
\end{tabular}


Table 4: Summary measures of pupil learning, class and school quality by home advantage

\begin{tabular}{llrrrrr}
\hline Quintile of home advantage & & $\mathbf{1}$ & $\mathbf{2}$ & $\mathbf{3}$ & $\mathbf{4}$ & $\mathbf{5}$ \\
\hline Pupil level difference: & Maths & -0.95 & $-6.12^{* * *}$ & $-2.53^{*}$ & 1.23 & $7.13^{* * *}$ \\
\cline { 2 - 8 } Actual-expected score & Vietnamese & -1.78 & $-4.73^{* * *}$ & 0.00 & -1.88 & $7.04 * * *$ \\
\hline
\end{tabular}

Table 5: School-level quality indicators by pupil home advantage

\begin{tabular}{|c|c|c|c|c|c|c|c|}
\hline Home advantage quintile & 1 & 2 & 3 & 4 & 5 & Total & $\begin{array}{r}\text { Diff } \\
\text { Q5-Q1 } \\
\end{array}$ \\
\hline Each Grade 5 class has its own classroom & 0.93 & 1.00 & 1.00 & 1.00 & 1.00 & 0.98 & $0.07 * * *$ \\
\hline School has computer facilities & 0.27 & 0.37 & 0.39 & 0.50 & 0.72 & 0.46 & $0.46^{* * *}$ \\
\hline School has internet access for pupils & 0.21 & 0.31 & 0.35 & 0.45 & 0.69 & 0.42 & $0.48 * * *$ \\
\hline School has working electricity & 0.90 & 0.94 & 0.92 & 0.95 & 0.97 & 0.94 & $0.07 * * *$ \\
\hline School assets (index) $)^{11}$ & -0.07 & 0.65 & 0.68 & 0.89 & 1.15 & 0.68 & $1.22 * * *$ \\
\hline School has library & 0.60 & 0.79 & 0.82 & 0.90 & 0.96 & 0.82 & $0.36 * * *$ \\
\hline Principal experience (years) & 10.22 & 9.99 & 10.88 & 9.81 & 9.59 & 10.08 & $-0.63 * *$ \\
\hline Principal has university degree & 0.55 & 0.69 & 0.71 & 0.79 & 0.87 & 0.73 & $0.34 * * *$ \\
\hline Principal has $\geq 3$ year's pre-service training & 0.93 & 0.92 & 0.91 & 0.98 & 0.99 & 0.95 & $0.06 * * *$ \\
\hline Principal in-service training (days per year) & 19.29 & 14.59 & 14.84 & 16.2 & 16.22 & 16.23 & $-3.07 * * *$ \\
\hline Principal 'excellent teacher' at $\geq$ district level & 0.54 & 0.63 & 0.64 & 0.69 & 0.79 & 0.66 & $0.25 * * *$ \\
\hline School unforeseen closures (days per year) & 0.53 & 0.97 & 1.23 & 1.16 & 0.92 & 0.96 & $0.38 * * *$ \\
\hline Visits by inspector (per year) & 4.46 & 5.11 & 5.49 & 5.97 & 7.26 & 5.72 & $2.79 * * *$ \\
\hline School has problems of 'failing infrastructure' & 0.32 & 0.33 & 0.29 & 0.22 & 0.16 & 0.26 & $-0.16 * * *$ \\
\hline
\end{tabular}

\footnotetext{
${ }^{11}$ Index from PCA of indicators of need for repairs, separate room for each Grade 5 class, library, computers, electricity and internet
} 
Table 6: Class and teacher -level quality indicators by pupil home advantage

\begin{tabular}{|c|c|c|c|c|c|c|c|}
\hline Home advantage quintile & 1 & 2 & 3 & 4 & 5 & Total & $\begin{array}{r}\text { Diff } \\
\text { Q5-Q1 }\end{array}$ \\
\hline & Class & & & & & & \\
\hline Pupils per class & 22.98 & 27.1 & 28.61 & 30.75 & 34.83 & 29.06 & $11.85^{* * *}$ \\
\hline Classroom needs major repairs & 0.13 & 0.15 & 0.15 & 0.09 & 0.08 & 0.12 & $-0.06 * * *$ \\
\hline Class assets (index) ${ }^{12}$ & -0.42 & 0.12 & 0.12 & 0.26 & 0.32 & 0.09 & $0.74 * * *$ \\
\hline Specialist teacher (Vietnamese) & 0.18 & 0.22 & 0.24 & 0.25 & 0.22 & 0.22 & $0.04 * *$ \\
\hline Specialist teacher (maths) & 0.21 & 0.24 & 0.28 & 0.24 & 0.23 & 0.24 & 0.02 \\
\hline Pupils with maths textbook 'for own use' & 0.93 & 0.96 & 0.97 & 0.97 & 0.98 & 0.96 & $0.04 * * *$ \\
\hline Pupils with Viet. textbook 'for own use' & 0.95 & 0.96 & 0.98 & 0.99 & 0.98 & 0.97 & $0.03^{* * *}$ \\
\hline Teaching time in Vietnamese (hours/week) & 5.38 & 5.55 & 5.49 & 5.75 & 5.75 & 5.59 & $0.37 * * *$ \\
\hline Teaching time in Maths (hours/week) & 3.56 & 3.73 & 3.69 & 3.91 & 3.94 & 3.77 & $0.38^{* * *}$ \\
\hline Classroom has a computer & 0.02 & 0.05 & 0.07 & 0.13 & 0.22 & 0.10 & $0.20^{* * *}$ \\
\hline Classroom has teacher's desk & 0.95 & 1.00 & 1.00 & 1.00 & 1.00 & 0.99 & $0.05^{* * *}$ \\
\hline Classroom has blackboard & 0.99 & 0.99 & 1.00 & 1.00 & 0.99 & 0.99 & 0.00 \\
\hline Classroom has adequate electric lighting & 0.88 & 0.98 & 0.99 & 0.99 & 0.99 & 0.97 & $0.11^{* * *}$ \\
\hline Problem of interruptions to teaching & 0.16 & 0.26 & 0.32 & 0.35 & 0.29 & 0.28 & $0.13^{* * *}$ \\
\hline Problem of lack of materials among pupils & 0.50 & 0.42 & 0.41 & 0.44 & 0.32 & 0.41 & $-0.18 * * *$ \\
\hline Classroom has adequate furniture & 1.00 & 0.99 & 0.99 & 0.99 & 0.99 & 0.99 & $-0.01 * *$ \\
\hline Classroom has books other than textbooks & 0.57 & 0.74 & 0.75 & 0.83 & 0.84 & 0.75 & $0.27 * * *$ \\
\hline \multirow[t]{2}{*}{ Periods of instruction per week } & 27.02 & 28.76 & 28.7 & 30.13 & 30.48 & 29.07 & $3.46 * * *$ \\
\hline & Teacher & & & & & & \\
\hline Teacher absence (days per year) & 1.63 & 2.17 & 1.99 & 3.58 & 2.56 & 2.39 & $0.93 *$ \\
\hline Teacher evaluation (times per year) & 7.87 & 6.87 & 7.37 & 6.75 & 6.90 & 7.14 & $-0.97 * * *$ \\
\hline Teacher in-service training (days per year) & 8.47 & 6.88 & 7.05 & 7.23 & 8.03 & 7.55 & -0.44 \\
\hline Teacher experience (years) & 17.26 & 16.94 & 18.00 & 17.01 & 17.92 & 17.44 & $0.66^{*}$ \\
\hline Teacher maths score & 11.83 & 11.86 & 11.88 & 12.42 & 12.2 & 12.04 & $0.37 * * *$ \\
\hline Teacher Vietnamese score & 16.57 & 16.62 & 16.72 & 17.28 & 17.7 & 17.00 & $1.13^{* * *}$ \\
\hline Teachers with degrees & 0.78 & 0.81 & 0.84 & 0.84 & 0.87 & 0.83 & $0.09 * * *$ \\
\hline No. of homework tasks in Viet. (per wk.) & 4.21 & 4.40 & 4.51 & 4.46 & 3.05 & 4.09 & $-1.16^{* * *}$ \\
\hline No. of homework tasks in maths (per wk.) & 5.15 & 5.52 & 5.61 & 5.69 & 4.06 & 5.16 & $-1.09 * * *$ \\
\hline Teacher's workload (periods per week) & 23.05 & 23.16 & 22.85 & 23.65 & 23.59 & 23.27 & $0.54 * * *$ \\
\hline Teacher always checks homework (maths) ${ }^{13}$ & 0.44 & 0.40 & 0.41 & 0.41 & 0.40 & 0.41 & $-0.04 *$ \\
\hline Teacher always checks homework (Viet.) ${ }^{14}$ & 0.37 & 0.28 & 0.33 & 0.33 & 0.27 & 0.31 & $-0.10^{* * *}$ \\
\hline Excellent teacher (district level or higher) & 0.72 & 0.66 & 0.66 & 0.63 & 0.66 & 0.67 & $-0.06 * * *$ \\
\hline Teacher has $\geq 3$ years pre-service training & 0.78 & 0.80 & 0.84 & 0.84 & 0.88 & 0.83 & $0.10^{* * *}$ \\
\hline
\end{tabular}

\footnotetext{
${ }^{12}$ Index from PCA of indicators for materials and facilities available comprising lighting, fan, reading books, chalk-board, cabinets, wall-map, teacher's desk, television, radio, computer and overhead projector

${ }^{13}$ Based on pupils' reports

${ }^{14}$ Based on pupils' reports
} 
Table 7: Pupil-level indicators of learning opportunities by pupil home advantage

\begin{tabular}{|c|c|c|c|c|c|c|c|}
\hline Home advantage quintile & 1 & 2 & 3 & 4 & 5 & Total & $\begin{array}{r}\text { Diff } \\
\text { Q5-Q1 }\end{array}$ \\
\hline Travel time to school (minutes) & 15.82 & 12.62 & 11.58 & 10.7 & 10.41 & 12.16 & $-5.42 * * *$ \\
\hline Ever repeated a grade & 0.10 & 0.04 & 0.03 & 0.02 & 0.03 & 0.04 & $-0.07 * * *$ \\
\hline Reads books outside school & 0.71 & 0.87 & 0.90 & 0.94 & 0.94 & 0.87 & $0.23 * * *$ \\
\hline Uses a computer outside school & 0.06 & 0.14 & 0.21 & 0.33 & 0.69 & 0.30 & $0.63 * * *$ \\
\hline Materials for learning maths (index) ${ }^{15}$ & -0.44 & -0.01 & 0.06 & 0.13 & 0.22 & 0 & $0.66^{* * *}$ \\
\hline Materials for learning Vietnamese (index) $)^{16}$ & -0.58 & -0.06 & 0.04 & 0.16 & 0.38 & 0 & $0.96 * * *$ \\
\hline Time spent on homework per day & 1.63 & 1.89 & 1.97 & 1.94 & 1.94 & 1.88 & $0.31 * * *$ \\
\hline Attends extra classes in any subject & 20.1 & 32.4 & 38.4 & 41.6 & 58.1 & 38.8 & $0.38 * * *$ \\
\hline Hours of extra classes in maths (per week) & 0.66 & 1.11 & 1.29 & 1.27 & 1.93 & 1.28 & $1.27 * * *$ \\
\hline Hours of extra classes in Viet. (per week) & 0.60 & 0.91 & 0.96 & 0.95 & 1.54 & 1.01 & $0.94 * * *$ \\
\hline Hours of extra classes in other subjects & 0.08 & 0.26 & 0.34 & 0.41 & 1.00 & 0.44 & $0.91 * * *$ \\
\hline Days absent ${ }^{17}$ & 1.18 & 0.62 & 0.57 & 0.55 & 0.60 & 0.70 & $0.57 * * *$ \\
\hline
\end{tabular}

Table 8: Characteristics of pupils' class peers by home advantage

\begin{tabular}{|c|c|c|c|c|c|c|c|}
\hline Home advantage quintile & 1 & 2 & 3 & 4 & 5 & Total & $\begin{array}{r}\text { Diff } \\
\text { Q1-5 }\end{array}$ \\
\hline \multicolumn{8}{|c|}{ Mean class peer background characteristics } \\
\hline Male & 0.51 & 0.51 & 0.51 & 0.51 & 0.51 & 0.51 & 0.00 \\
\hline Age & 10.35 & 10.3 & 10.29 & 10.27 & 10.26 & 10.29 & $0.08 * * *$ \\
\hline Mathematics (R1) & 487.63 & 500.15 & 504.2 & 512.68 & 536.68 & 507.78 & $-49.05 * * *$ \\
\hline Vietnamese (R1) & 483.96 & 504.43 & 507.82 & 516.53 & 540.58 & 510.05 & $-56.62 * * *$ \\
\hline \multicolumn{8}{|c|}{ Mean class peer learning opportunities } \\
\hline $\begin{array}{l}\text { Travel time to school (in } \\
\text { minutes) }\end{array}$ & 13.79 & 12.44 & 11.76 & 11.37 & 10.69 & 12.03 & $3.10^{* * *}$ \\
\hline Ever repeated a grade & 0.05 & 0.04 & 0.04 & 0.03 & 0.02 & 0.04 & $-0.02 * * *$ \\
\hline Reads books outside school & 0.83 & 0.89 & 0.89 & 0.91 & 0.93 & 0.89 & $-0.10 * * *$ \\
\hline $\begin{array}{l}\text { Uses a computer outside } \\
\text { school }\end{array}$ & 0.17 & 0.24 & 0.26 & 0.33 & 0.55 & 0.31 & $-0.38 * * *$ \\
\hline $\begin{array}{l}\text { Materials for learning maths } \\
\text { (index) }\end{array}$ & -0.16 & 0.05 & 0.05 & 0.09 & 0.19 & 0.04 & $-0.35 * * *$ \\
\hline $\begin{array}{l}\text { Materials for learning } \\
\text { Vietnamese (index) }\end{array}$ & -0.24 & 0.03 & 0.05 & 0.12 & 0.31 & 0.05 & $-0.55^{* * *}$ \\
\hline $\begin{array}{l}\text { Time spent on homework per } \\
\text { day }\end{array}$ & 1.82 & 1.88 & 1.94 & 1.94 & 1.89 & 1.89 & $-0.07 *$ \\
\hline $\begin{array}{l}\text { Hours of extra classes in } \\
\text { maths (per week) }\end{array}$ & 0.87 & 1.31 & 1.24 & 1.32 & 2.01 & 1.34 & $-1.14 * * *$ \\
\hline $\begin{array}{l}\text { Hours of extra classes in Viet. } \\
\text { (per week) }\end{array}$ & 0.77 & 1.07 & 0.91 & 1.00 & 1.56 & 1.05 & $-0.79 * * *$ \\
\hline Days absent ${ }^{18}$ & 0.77 & 0.57 & 0.56 & 0.55 & 0.53 & 0.59 & $0.24 * * *$ \\
\hline Home advantage quintile & 2.2 & 2.77 & 2.96 & 3.19 & 3.86 & 3.0 & $1.66^{* * *}$ \\
\hline
\end{tabular}

\footnotetext{
${ }^{15}$ Index from PCA of own maths textbook, other maths books, school bag, ruler, calculator

${ }^{16}$ Index from PCA of Vietnamese textbooks (volume 1 and 2), other Vietnamese school books, dictionary

${ }^{17}$ During the period between the first and second tests (approximately 8 months)

${ }^{18}$ During the period between the first and second tests (approximately 8 months)
} 
Table 9: Predictors of learning achievement in maths and Vietnamese

\begin{tabular}{|c|c|c|c|c|}
\hline & Maths OLS & Vietnamese OLS & Maths SFE & Vietnamese SFE \\
\hline Home advantage index & 0.5905 & 0.8925 & 0.4626 & $2.8648 * * *$ \\
\hline Time taken to get to school & $-0.4637 * * *$ & -0.2456 & $-0.5672 * * *$ & $-0.2937^{*}$ \\
\hline Grade repeater & $-23.5370 * * *$ & -8.7930 & $-25.3499 * * *$ & $-20.0485^{* * *}$ \\
\hline Reads books outside school & 2.5926 & $7.9548 *$ & 3.6339 & $10.9906 * *$ \\
\hline Uses a computer outside school & $6.9392 * *$ & 4.0164 & 4.8444 & 0.6792 \\
\hline Extra maths classes per week (hrs.) & -0.6665 & - & -0.5500 & - \\
\hline Extra Vietnamese classes per week (hrs.) & - & 0.3744 & - & -0.1820 \\
\hline Extra classes in other subjects per week & $1.8299 *$ & 0.7023 & $1.7761^{*}$ & 0.3740 \\
\hline Hours spent on homework & $2.9835 * *$ & 1.8314 & $3.1977 * *$ & $2.5996 *$ \\
\hline Class peer: mean Maths score & $0.1049 * * *$ & - & -0.0184 & - \\
\hline Class peer: mean Vietnamese score & - & 0.0310 & - & $-0.1333^{* *}$ \\
\hline Class peers: male (proportion) & $-26.1016 * *$ & $-58.5423 * * *$ & -22.8539 & -19.1208 \\
\hline Class peers: age in years (mean) & $52.1626 * * *$ & $25.4666^{*}$ & $115.9430 * * *$ & $119.5094 * * *$ \\
\hline Class peers: home advantage index & $-8.1513 * * *$ & -1.5330 & -4.4388 & $25.7479 * * *$ \\
\hline Class peers: grade repeaters (proportion) & $-180.5685 * * *$ & -4.4981 & $-190.0494 * * *$ & $-191.5038 * * *$ \\
\hline Class peers: read books outside of school & $22.1642 *$ & -7.6597 & 21.2555 & 16.4926 \\
\hline Class peers: use computers outside of & $60.5763 * * *$ & $19.3800 *$ & 14.1815 & $-42.5436 * *$ \\
\hline Class peers: extra maths classes per & $-2.7047 * *$ & - & -1.5289 & - \\
\hline Class peers: extra Viet. classes per week & - & $-5.7176 * * *$ & - & $-9.2912 * * *$ \\
\hline Class peers: extra other classes per week & $-9.1337 * * *$ & -0.1000 & -5.0276 & 1.1883 \\
\hline Class peers: days absent & $5.0821 * *$ & 1.5641 & $5.2007 *$ & -2.8326 \\
\hline Class size & $-1.0592 * * *$ & -0.2665 & $3.5344 * * *$ & 2.1890 \\
\hline Classroom needs major repairs & 5.0331 & $-13.3052 * * *$ & -5.8239 & $-28.2970 * * *$ \\
\hline Teacher specialised in Vietnamese & $-12.3923 * *$ & -6.2826 & $-31.8158 * * *$ & -10.0694 \\
\hline Teacher specialised in maths & $28.2407 * * *$ & $23.0772 * * *$ & $42.9122 * * *$ & $42.2369 * * *$ \\
\hline No. mins. class studies Viet. per week & 0.0018 & 0.0019 & $-0.3044 * * *$ & -0.0602 \\
\hline No. mins. class studies maths per week & -0.0516 & -0.0242 & -0.0187 & 0.0229 \\
\hline Class has a usable computer & 5.3797 & $19.6510 * * *$ & -8.9744 & $21.2892 *$ \\
\hline Interruptions to teaching & 5.3693 & -3.6391 & $-32.4590 * * *$ & $-12.8852 *$ \\
\hline Class has usable books other than & $8.4361 * *$ & 1.3734 & $-17.8187 * * *$ & $-12.4629 * *$ \\
\hline Total number of periods of instruction & $-1.2085^{* *}$ & -0.8721 & 2.1029 & $-5.5209 * * *$ \\
\hline Teacher days absent in last academic & -0.1585 & $-0.2671 * *$ & $-0.2611 *$ & $-0.4685^{* * *}$ \\
\hline Teacher evaluation: number last year & $0.6987 * * *$ & $1.1694 * * *$ & 0.5009 & 0.1768 \\
\hline Teacher days in-service training last year & $-0.4760 * *$ & 0.2355 & -0.2997 & $-1.6568 * * *$ \\
\hline Teacher time taken to travel to school & $-0.8442 * * *$ & 0.0329 & 0.3989 & 0.5215 \\
\hline Teacher experience (years) & $0.5586 * *$ & $1.2788 * * *$ & $1.2062 * * *$ & $1.0117 * * *$ \\
\hline Teacher maths PCK score & $2.1097 * * *$ & $1.2514^{*}$ & $1.4932 *$ & 0.2245 \\
\hline Teacher Vietnamese PCK score & $0.9717 *$ & -0.5430 & $2.0536 * *$ & $-1.7092 *$ \\
\hline Teacher has $\geq 3$ years pre-service training & 1.0509 & $8.4794 * * *$ & -1.4743 & -0.6129 \\
\hline Vietnamese homework per week (no. of & -0.8095 & -0.8145 & $-1.9062 *$ & $2.0412 *$ \\
\hline Maths homework per week (no. of tasks) & $1.0132 *$ & 0.7296 & 0.4706 & $-3.2829 * * *$ \\
\hline Teacher always checks maths homework & $8.3210 * *$ & -2.2805 & 1.0179 & -2.5427 \\
\hline Teacher always checks Vietnamese & $-5.9379 *$ & -4.3226 & $-9.1556^{* * *}$ & -3.9254 \\
\hline Observations & 2,284 & 2,287 & 2,455 & 2,458 \\
\hline R-squared & 0.446 & 0.376 & 0.336 & 0.302 \\
\hline Number of school fixed effects & & & 81 & 81 \\
\hline
\end{tabular}

